\title{
Shear Stress Induction of the Tissue Factor Gene
}

\author{
Ming-Chao Lin, ${ }^{\star}$ Fanny Almus-Jacobs, ${ }^{*}$ Hsuan-Hsu Chen, ${ }^{\star}$ Graham C.N. Parry, ${ }^{\ddagger}$ Nigel Mackman, ${ }^{\ddagger}$ John Y-J. Shyy, ${ }^{\star}$ \\ and Shu Chien* \\ *Department of Bioengineering and Institute for Biomedical Engineering, University of California, San Diego, La Jolla, California 92093- \\ 0412; ${ }^{\ddagger}$ Department of Immunology and Vascular Biology, The Scripps Research Institute, La Jolla, California 92037
}

\begin{abstract}
Using flow channel, we report that the application of a laminar shear stress induced a transient increase of tissue factor (TF) procoagulant activity in human umbilical vein endothelial cells (HUVEC), which was accompanied by a rapid and transient induction of the TF mRNA in the HUVEC. Functional analysis of the $2.2 \mathrm{~kb}$ TF $5^{\prime}$ promoter indicated that a GC-rich region containing three copies each of the EGR-1 and Sp1 sites was required for induction. Mutation of the Sp1 sites, but not the EGR-1 sites, attenuated the response of TF promoter to shear stress. Thus, Sp1 is a newly defined shear stress responsive element. Electrophoretic mobility shift assays showed there was no increase in binding of nuclear extracts from sheared cells to an Sp1 consensus site. In contrast, immunoblotting of these nuclear extracts with antibody against transcription factor Sp1 demonstrated that shear stress increased the phosphorylation of Sp1. We also showed that shear stress, like the phosphatase inhibitor okadaic acid, increased the transcriptional activity of Sp1. These findings suggest that the shear stress induction of TF gene expression is mediated through an increased Sp1 transcriptional activity with a concomitant hyperphosphorylation of Sp1. (J. Clin. Invest. 1997. 99:737-744.) Key words: atherosclerosis - thrombosis - gene expression • hemodynamics $\bullet$ signal transduction
\end{abstract}

\section{Introduction}

The pathophysiological role of hemodynamic forces in atherogenesis is manifested by the focal nature of the disease. In human patients and animal models of atherosclerosis, the atherosclerotic lesions distribute focally in the bifurcations and curved regions of the arterial tree where the blood flow is disturbed with flow separation and the wall shear stress is low and unsteady (1). We hypothesize that the localization of the disease in the vessel wall is related to the activation of a number of atherosclerosis-related genes by the local hemodynamic forces. This is supported by two recent in vivo experiments in animal models. First, the expression of intercellular adhesion

Address correspondence to John Y-J. Shyy, Ph.D., Department of Bioengineering, University of California, San Diego, La Jolla, CA 92093-0412. Phone: 619-822-0785, 619-534-5251; FAX: 619-534-3658; E-mail: Shyy@heart3.ucsd.edu

Received for publication 17 June 1996 and accepted in revised form 9 December 1996.

J. Clin. Invest.

(C) The American Society for Clinical Investigation, Inc. 0021-9738/97/02/0737/08 \$2.00

Volume 99, Number 4, February 1997, 737-744 molecule 1 (ICAM-1) ${ }^{1}$ in the arterial trees of apoE knock out mice localizes at the lesion-prone areas (2). Second, high shear stress upregulates ICAM-1 and vascular cell adhesion molecule-1 (VCAM-1) in rabbits, whereas low shear stress upregulates VCAM-1 and downregulates ICAM-1 (3).

Tissue factor (TF), a transmembrane glycoprotein with a molecular mass of $45 \mathrm{kD}$, is an initiator of the coagulation protease cascade. TF binds factor VII to form a TF/VIIa complex that subsequently activates factor $\mathrm{X}$ to $\mathrm{Xa}$, which ultimately catalyzes the conversion of prothrombin to thrombin (4). The expression of TF mRNA in normal vascular endothelial cells (ECs) in vivo is undetectable. Its expression, however, is increased in a variety of pathological conditions, including in atherosclerotic plaques $(5,6)$ and in arterial smooth muscle cells after balloon injury (7). Chemical stimuli such as phorbol ester 12-O-tetradecanoyl-13-phorbol-acetate (TPA), tumor necrosis factor- $\alpha$ (TNF- $\alpha)$, bacterial endotoxin LPS, and IL-1 $\beta$ induce the expression of TF mRNA in cultured ECs (8-11). TF was also induced in fibroblasts and COS-7 cells by serum and growth factors, including platelet-derived growth factor (PDGF), basic-fibroblast growth factor (b-FGF), and transforming growth factor- $\beta$ (TGF- $\beta)(12-14)$. In the $5^{\prime}$ promoter region of the TF gene, there are several cis-elements, including TPA-responsive elements (TRE), кB, Sp1, and EGR-1 (14). These elements play critical roles in response to various stimuli (14-16).

In the past few years, flow channels have been widely used as an in vitro system to investigate the responses of cultured ECs to hemodynamic forces at the cellular and molecular levels $(17,18)$. Such studies have demonstrated increased levels of transcripts for tissue plasminogen activator, PDGF, the protooncogenes c-fos, c-jun, and c-myc, ICAM-1, endothelin-1, b-FGF, VCAM-1, heparin-binding epidermal growth factorlike growth factor, and TGF- $\beta$ (19-28), among others, in cultured vascular ECs subjected to shear stress. We have also shown that the application of a shear stress regulates the expression of the monocyte chemotactic protein-1 (MCP-1) gene in various types of cells, including vascular ECs and the epithelial cells (29). Functional analysis of the $5^{\prime}$ promoter of the gene demonstrated that shear-induced expression of MCP-1 is mediated through a divergent TRE (30). Cis-elements such as the shear stress responsive element (SSRE, with the sequence of GAGACC) and $\kappa \mathrm{B}$ have also been shown to be shear in-

1. Abbreviations used in this paper: $\mathrm{BAEC}$, bovine aortic endothelial cells; $\beta$-gal, $\beta$-galactosidase; EC, endothelial cells; HUVEC, human umbilical vein endothelial cells; ICAM-1, intercellular adhesion molecule; MCP-1, monocyte chemotactic protein-1; OKA, okadaic acid; PDGF, platelet-derived growth factor; TF, tissue factor; TNF- $\alpha$, tumor necrosis factor- $\alpha$, TPA, 12- $O$-tetradecanoyl-13-phorbol-acetate; TRE, TPA-responsive elements; VCAM-1, vascular cell adhesion molecule-1. 
ducible (31-34). Thus, it is very possible that multiple cis-elements coexist as "shear stress responsive elements" in the distal ends of the signaling events elicited by shear stress.

Since both shear stress and cytokines can activate a similar group of common target genes, we examine whether shear stress can regulate the expression of the TF gene in ECs. With the existence of multiple cis-elements, the TF $5^{\prime}$ promoter also provides a model to study the interactions among these cis-elements in regulating gene expression in response to shear stress. We report that shear stress induces the TF gene, which is mediated by cis-element Sp1. These transcriptional events are upregulated with a concomitant hyperphosphorylation on transcription factor $\mathrm{Sp} 1$.

\section{Methods}

Endothelial cell culture. Human umbilical vein endothelial cells (HUVEC) were isolated from fresh umbilical cords according to the procedures described by Jaffe et al. (35). Cells prior to passage three were cultured in endothelial cell growth medium (EGM, Clonetics Corp., San Diego, CA) supplemented with $10 \%$ FBS (GIBCO-BRL, Gaithersburg, MD). Bovine aortic endothelial cells (BAEC) prior to passage 10 were maintained in DMEM media (GIBCO-BRL) supplemented with $10 \%$ FBS. All cell cultures were maintained in a humidified $5 \% \mathrm{CO}_{2}-95 \%$ air incubator at $37^{\circ} \mathrm{C}$.

Shear stress experiments. Cells cultured on glass slides were subjected to a laminar shear stress in a rectangular flow channel. The shear stress was increased suddenly from 0 (static) $-12 \mathrm{dyn} / \mathrm{cm}^{2}$ and was maintained at this level for the time periods described in each of the experiments. The flow experiments were performed by using the system described by Frangos et al. (36) with minor modifications so that multiple slides could be sheared simultaneously. The $\mathrm{pH}$ of the medium was maintained constant by gassing with a mixture of $5 \%$ $\mathrm{CO}_{2}$ and $95 \%$ air, and the temperature was maintained at $37^{\circ} \mathrm{C}$ by immersing the flow system in a water bath. Experiments were also performed on cells in flow chambers not exposed to shear stress; the results obtained from such unsheared specimens were used as the static controls.

RNA isolation and Northern blot analysis. Total cellular RNA were isolated from sheared or static cells by using the guanidinium isothiocyanate method (37). The isolated RNA were electrophoresed on a $1.5 \%$ formaldehyde agarose gel and transferred to a nylon membrane for hybridization. The probe used was a ${ }^{32} \mathrm{P}$-labeled $1.5 \mathrm{~kb}$ TF cDNA to detect the expressed TF mRNA.

Plasmids and DNA transfection. All the plasmids used in this study have been described elsewhere $(14,16,38,39)$. DNA plasmids were transfected into BAEC at $70 \%$ confluence using the lipofectamine method (GIBCO-BRL). The pSV- $\beta$-galactosidase ( $\beta$-gal) plasmid, which contains a $\beta$-gal gene driven by the SV40 promoter and enhancer, was cotransfected to monitor the transfection efficiency. After incubation in $5 \% \mathrm{CO}_{2}-95 \%$ air, at $37^{\circ} \mathrm{C}$ for $6 \mathrm{~h}, \mathrm{DMEM}$ media containing $13 \%$ FBS were added to the transfected cells for incubation of another $24-48 \mathrm{~h}$ to reach confluence. In general, $10-15 \%$ of the cells in the tissue culture flasks were transfected, as detected by $\mathrm{X}$-gal staining. The cells were then seeded on glass slides for either shear stress experiments or kept as static controls. To release the reporter protein luciferase and $\beta$-gal, the cells were lysed with a lysis buffer containing Triton X-100. ATP and luciferin were added to the lysate in a luminometer for measuring the total light output. Separately, the levels of $\beta$-gal were assayed by adding the substrate, o-nitrophenyl- $\beta$-D-galactopyranoside (ONPG) to the cell lysate and incubated at $37^{\circ} \mathrm{C}$ for $1 \mathrm{~h}$. The reaction was quenched by the addition of $\mathrm{Na}_{2} \mathrm{CO}_{3}$, and the absorbance at $420 \mathrm{~nm}$ was recorded. Since pSV$\beta$-galactosidase is not induced by shear stress (unpublished results), the expression of luciferase was normalized to that of $\beta$-gal.

TF procoagulant activity assays. TF activities of the static or sheared HUVEC were assayed by measuring the enzymatic activation of factor X by the TF/VIIa complex. Monolayers of ECs were washed with PBS, followed by the addition of a reaction buffer containing $5 \mathrm{mM} \mathrm{Ca}^{+2}, 0.5 \mu \mathrm{g} / \mathrm{ml}$ recombinant factor VIIa, and $10 \mu \mathrm{g} / \mathrm{ml}$ factor X (Enzyme Research Laboratories, South Bend, IN). The reaction time was $15 \mathrm{~min}$ before the addition of a stopping buffer containing $6 \mathrm{mM}$ EDTA. With the addition of the chromogen, chromozym X (Boehringer-Mannheim, Indianapolis, IN), aliquots of samples were assayed for their absorbence at $410 \mathrm{~nm}$. The formation rates of factor Xa in various samples were calculated based on a standard curve which had been established by using known amounts of factor Xa (Boehringer-Mannheim).

Electrophoretic mobility shift assays (EMSA). Nuclear proteins were isolated from static or sheared cells according to published protocols (40). Oligonucleotide probes containing Sp1 with a sequence of ATTCGATCGGGGCGGGGCGAGC or EGR-1 with a sequence of CCCGGCGCGGGGGCGATTTCGAGTCA were labeled with ${ }^{32} \mathrm{P}$ either by the random primer method using $\left[\alpha{ }^{32} \mathrm{P}\right] \mathrm{dATP}$ or by the polynucleotide kinase method using $\left[\gamma^{-32} \mathrm{P}\right]$ ATP. $2 \mu \mathrm{g}$ of the isolated nuclear proteins were incubated with $2 \times 10^{4} \mathrm{cpm}$ of the labeled probe in the binding buffer containing $10 \mathrm{mM}$ Hepes, $\mathrm{pH} 7.9,5 \mathrm{mM}$ $\mathrm{MgCl}_{2}, 30 \mathrm{mM} \mathrm{KCl}$, and $5 \%$ of glycerol at room temperature for 30 min. The nucleotide-protein complexes were then electrophoresed in a $10 \%$ polyacrylamide gel, dried, and autoradiographed.

Immunoprecipitation and immunoblotting analysis. The isolated nuclear proteins were immunoprecipitated with a polyclonal antihuman Sp1 (Santa Cruz) and the immunoprecipitated complexes were electrophoresed on an $8 \%$ SDS polyacrylamide gel. In some of the experiments, the crude extracts were directly subjected to gel electrophoresis without immunoprecipitation. The proteins on the gel were transferred to nitrocellulose membrane, and probed with the same anti-human Sp1 antibody. The bands were detected by using a goat anti-rabbit IgG-HRP conjugate and the ECL detection system (Amersham Corp., Arlington Heights, IL).

\section{Results}

Shear stress increases the TF activity and TF $m R N A$ in ECs. To test whether shear stress induces TF expression at the protein level, confluent monolayers of HUVEC in a flow channel were subjected to a steady shear stress of $12 \mathrm{dyn} / \mathrm{cm}^{2}$ for various periods of time followed by chromogenic assays, in which we assayed the conversion of factor $X$ to Xa on the HUVEC monolayers. Fig. 1 indicates that the application of a shear stress induced a transient increase in procoagulant activity on the endothelial surface which peaked at 4-6 h. The activity returned to the level of static control at 10-12 $\mathrm{h}$. The cells were also treated with TPA for $6 \mathrm{~h}$ as a positive control, and the enhanced procoagulant activity was similar to that induced by shear stress. The specificity of the TF-mediated procoagulant activity in response to shear stress was verified using a polyclonal antibody against human TF. The addition of this antibody to the sheared cells $15 \mathrm{~min}$ prior to the addition of the reaction buffer abolished the activation of factor $\mathrm{X}$ by TF (data not shown). To test whether the shear stress-induced TF enzymatic activity is accompanied by an induction of TF mRNA, HUVEC were subjected to a shear stress of $12 \mathrm{dyn} / \mathrm{cm}^{2}$ followed by Northern blot analysis. Fig. 2 indicates that the TF mRNA in static controls (no shear) was undetectable. The application of shear stress for $1 \mathrm{~h}$ led to an induction of the TF mRNA, which reached a peak level at $2 \mathrm{~h}$, and was barely detectable $6 \mathrm{~h}$ after shearing. In addition, reverse transcriptionpolymerase chain reaction (RT-PCR) showed that shear stress also induced TF mRNA expression in BAEC (data not shown). Thus, shear stress, like other stimuli such as TPA, 


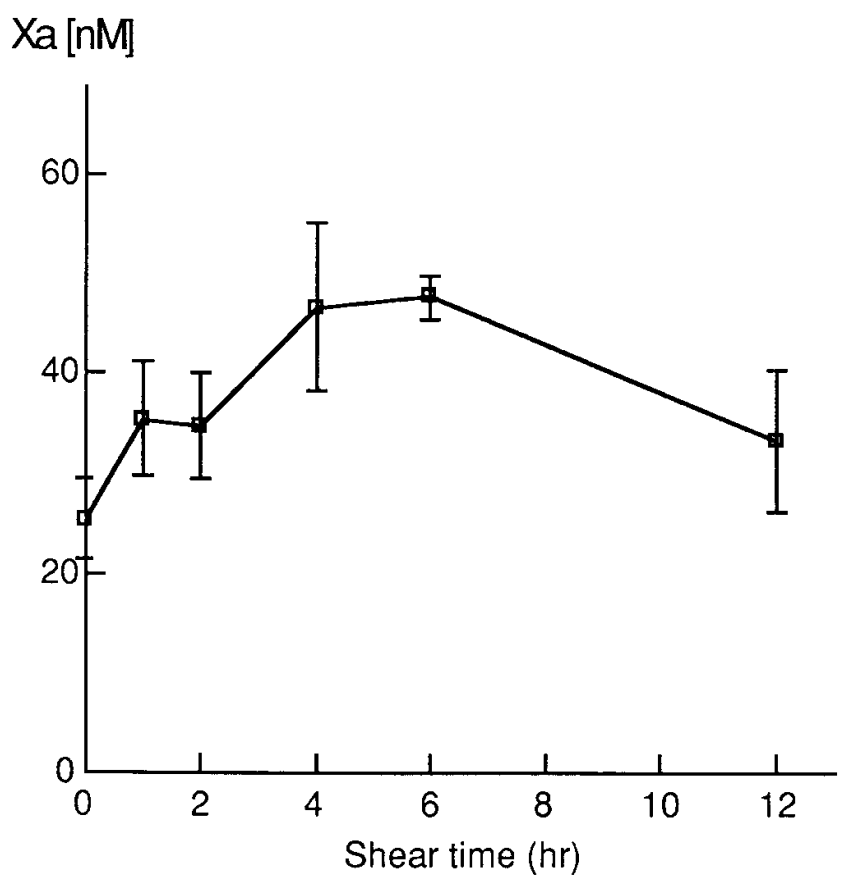

Figure 1. Shear stress elicits a transient response of TF procoagulant Xa activity in HUVEC. Cells were grown to confluence on the culture slides and were either subjected to a shear stress of $12 \mathrm{dyn} / \mathrm{cm}^{2}$ for a period of time as indicated or kept as static control represented by "time 0. ." The activities of TF in various samples are expressed as the rates of formation of factor Xa. Squares with bars represent the mean \pm SD from three different experiments.

LPS, IL-1 $\beta$, and TNF- $\alpha$, induces a time-dependent induction of TF mRNA in ECs.

Functional analysis of the TF $5^{\prime}$ promoter in response to shear stress. We have previously shown that the shear stress-

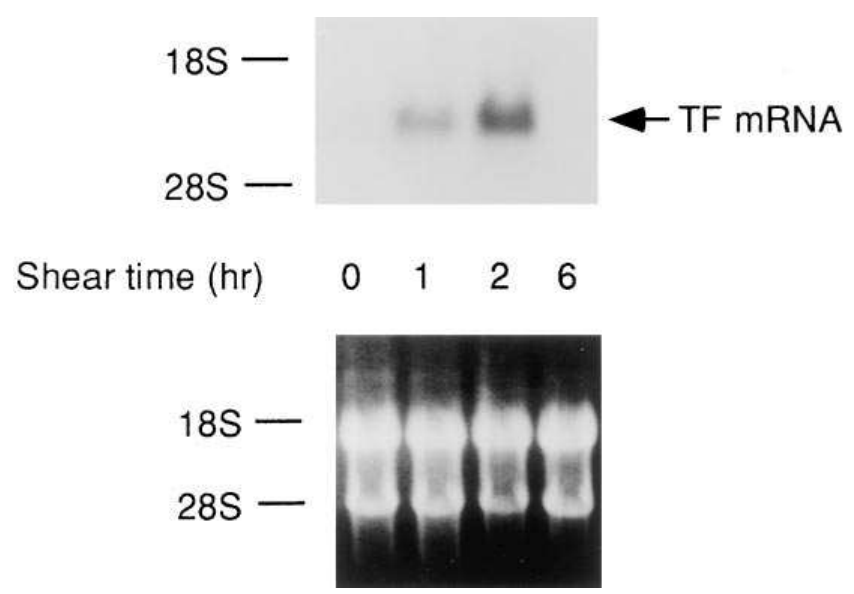

Figure 2. Shear stress induces a transient response of the TF transcripts in HUVEC. The experimental conditions were the same as those described in Fig. 1. Total cellular RNA were isolated from the cells and subjected to Northern blot analysis. The probe was a ${ }^{32} \mathrm{P}-$ labeled $1.5 \mathrm{~kb}$ TF cDNA. (Bottom) Ethidium bromide staining indicating that comparable amounts of RNA were loaded.

induced MCP-1 gene expression is mainly mediated through a divergent TRE (30). Several recent reports have demonstrated that $\kappa \mathrm{B}$ binding sites in several genes are also shear responsive (31-34). To test whether the two copies of TRE (nt -217 and $\mathrm{nt}-204$ in reference to the transcription initiation site) and the $\kappa \mathrm{B}(\mathrm{nt}-179)$ or other unidentified shear stress responsive elements in the TF promoter mediate the response to shear stress, TF 5' promoter deletion constructs were transfected into BAEC which were then subjected to shear stress/luciferase assays. As shown in Fig. 3, the application of a shear stress of $12 \mathrm{dyn} / \mathrm{cm}^{2}$ for $8 \mathrm{~h}$ resulted in a 5-7-fold induction of reporter activity in constructs PL1-PL5, which contained at least 209 bp

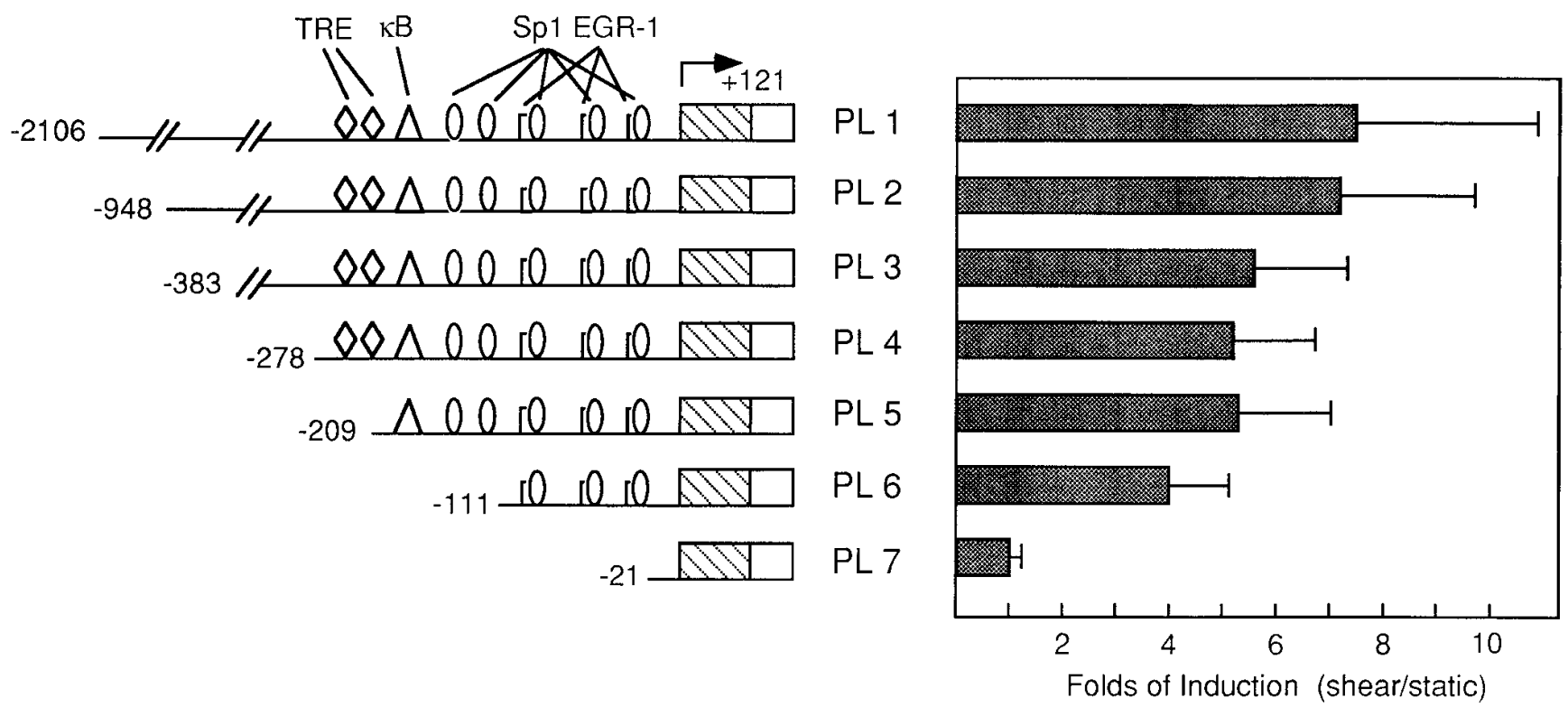

Figure 3. Functional analysis of the $5^{\prime}$ deletion constructs of the TF gene in terms of their responses to shear stress. The various constructs containing different lengths of the TF promoter linked to the luciferase reporter were transfected into BAEC. The conditions for shear stress experiments were the same as those described in Fig. 1, except that the cells were sheared for $8 \mathrm{~h}$ followed by the luciferase activities assays. The folds of induction were the luciferase activities in the experimental cells normalized for transfection efficiency (determine from $\beta$-galactosidase activities) compared to those in controls. The error bars represent the SD from at least three different experiments. 
of the promoter upstream of the transcription initiation site. Deletion of the TRE sites (i.e., compare PL5 to PL4) did not affect the induction by shear stress. The removal of $\kappa \mathrm{B}$ (nt -209 to -111 ; i.e., compare PL6 to PL5) decreased the basal level expression by one-half (data not shown). However, shear stress still induced a fourfold increase in reporter activity in PL6. When the GC-rich region containing EGR-1 and Sp1 sites was deleted (i.e., compare PL7 to PL6), the induction by shear stress, as well as basal expression, was abolished. We have also performed shear stress/luciferase assays on a mutant with site-specific mutation at the two TRE sites. The fold of induction by shear stress for this plasmid construct was not significantly different from those for the wild type PL4 and PL5 (data not shown). In addition, shear stress induced an eightfold increase in the luciferase activity of p2506, a chimeric construct comprised of three copies of the EGR-1/Sp1 (nt -96 to -65), an SV40 promoter, and a luciferase reporter (data not shown). Taken together, these data suggest that the GC-rich region plays a major role in the shear stress-induced TF promoter activity.

Sp1 is a shear stress responsive element. PL6 consists of a GC-rich region containing three copies each of EGR-1 and Sp1. To test whether the shear stress-induced PL6 activity is mediated through EGR-1 and/or Sp1, constructs pTF(EGR-1m)Luc
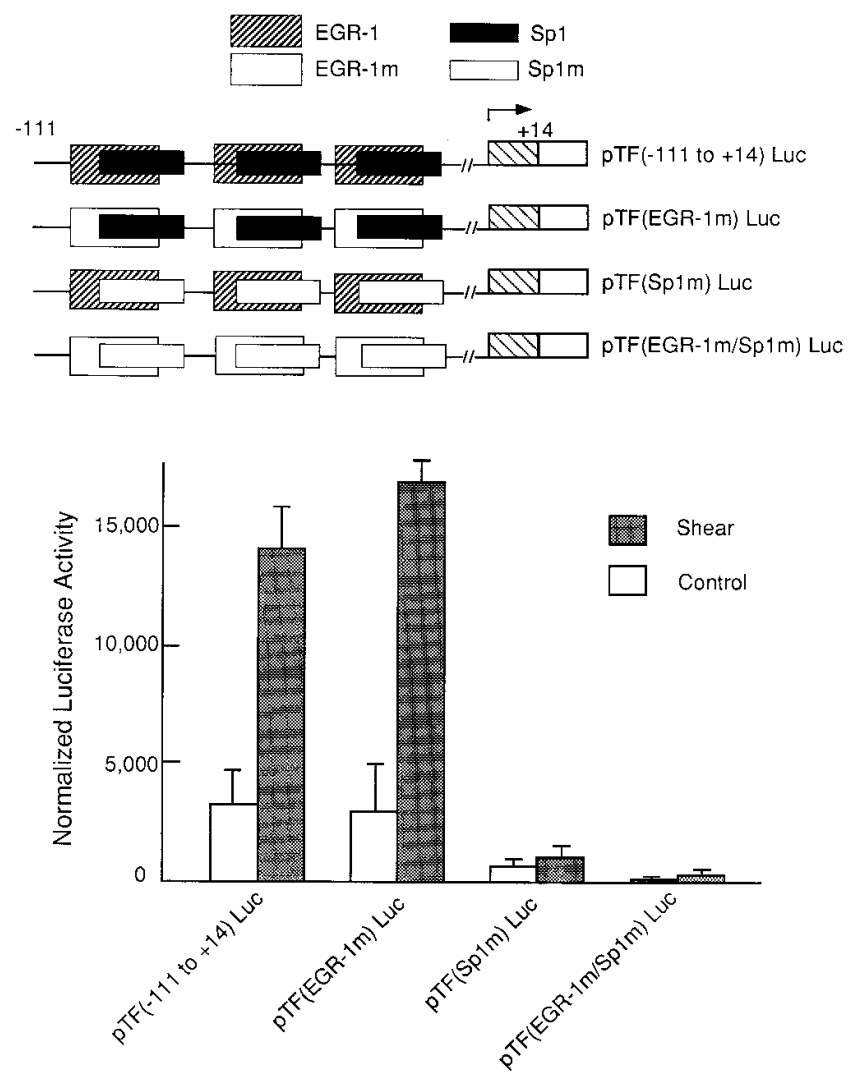

Figure 4. Cis-elements $\mathrm{Sp} 1$ constitute a shear stress responsive element. Top shows the various plasmids containing the wild type EGR-1 sites (hatched boxes), wild type Sp1 sites (filled boxes) and/or mutations in these sites (empty boxes) were transfected into BAEC for shear stress/luciferase assays. The results on the normalized luciferase activity after the use of these constructs are shown in the bar diagram, bottom. The bars represent the SD from at least three different experiments. (mutated EGR-1 and wild type Sp1) and pTF(Sp1m)Luc (mutated $\mathrm{Sp} 1$ and wild type EGR-1) were transiently transfected into BAEC for shear stress/luciferase assays. For pTF(EGR$1 \mathrm{~m})$ Luc (mutated EGR-1), the basal expression and the folds of induction by shear stress were virtually the same as that in the wild type (Fig. 4). In contrast, mutation of Sp1, i.e., pTF $(\mathrm{Sp} 1 \mathrm{~m})$ Luc, markedly reduced the basal expression and the shear inducibility. For pTF(Sp1m/EGR-1m)Luc, in which both EGR-1 and Sp1 had been mutated, the basal expression and the shear inducibility were comparable to those of pTF(Sp1m)Luc, in which only Sp1 had been mutated. Thus, Sp1, but not EGR-1, is a shear stress responsive element in the $5^{\prime}$ promoter of the TF gene.

Shear stress does not increase the Spl binding to its target sequence. Promoter analysis suggested that the induction of the $\mathrm{TF}$ gene by shear stress is mediated by Sp1. To investigate the possible mechanisms by which shear stress increases Sp1 activity, we prepared nuclear proteins from both sheared cells and static controls. The nuclear extracts were used in EMSA with an oligonucleotide containing an Sp1 binding site as a probe. As shown in Fig. 5, nuclear extracts from static controls bind to

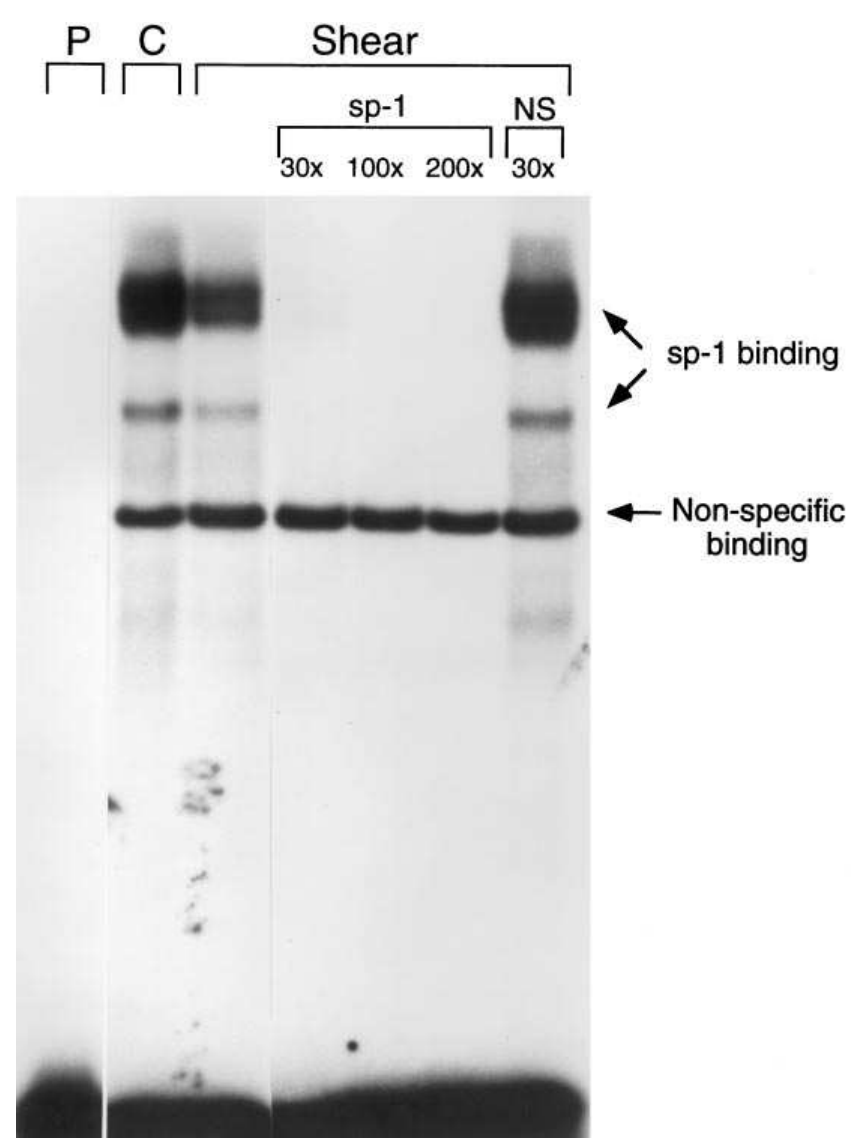

Figure 5. Electrophoretic mobility shift assay indicating that the nuclear factors isolated from the sheared cells do not show an increased binding to the $\mathrm{Sp} 1$ site. The oligonucleotide sequence of the labeled probe is 5'-ATTCGATCGGGGCGGGGCGAGC-3' (Sp1 site underlined). $P$ denotes free probe. $C$ and Shear represent nuclear extracts isolated from static HUVEC control and HUVEC subjected to a shear stress of $12 \mathrm{dyn} / \mathrm{cm}^{2}$ for $20 \mathrm{~min}$, respectively. $N S$ in the competition experiments was a nonsense oligonucleotide with a sequence of 5'-CGCTTGATTAAGGAGCCGGAA-3' . 
A.

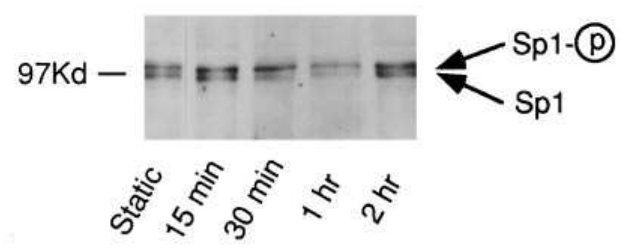

B.

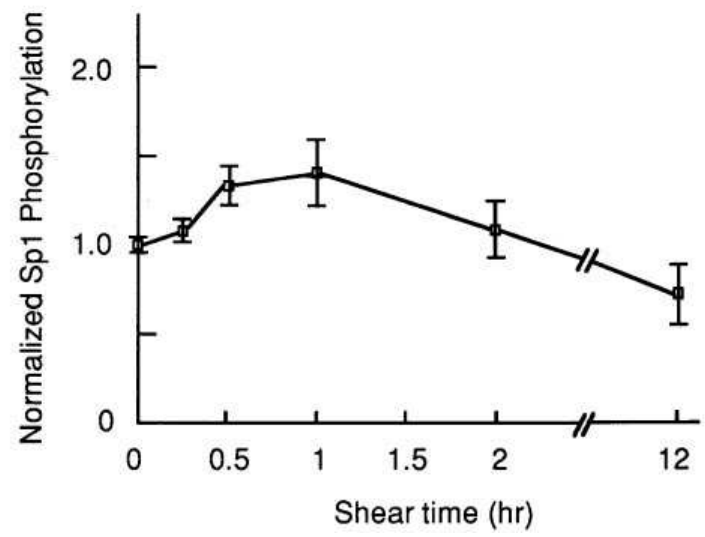

Figure 6. A, Shear stress increases the phosphorylation of transcription factor Sp1. Nuclear proteins were isolated from BAEC subjected to a shear stress of $12 \mathrm{dyn} / \mathrm{cm}^{2}$ for different durations of time. The upper and lower bands are the phosphorylated $\mathrm{Sp} 1$ and its unphosphorylated form, respectively, both of which are recognized by a polyclonal anti-human Sp1. The molecular weight markers are shown on the left. $B$, Densitometry analyses on Sp1 bands obtained from five separate experiments show that shear stress induces a transient increase in Sp1 phosphorylation. The normalized Sp1 phosphorylation is defined as the ratio of phosphorylated form to total Sp1 protein detected at each time point normalized to this ratio in the static controls (time 0). The error bars represent the SD.

the labeled probe. Nuclear extracts from cells sheared for 20 min did not show an increase in binding to the labeled probe. The specificity of Sp1 binding to its target sequence was determined by competition experiments in which the binding was eliminated using a 30 -fold molar excess of the unlabeled probe. A nonsense sequence did not compete with the labeled Sp1 probe for binding of nuclear proteins. An oligonucleotide spanning the sequence from $\mathrm{nt}-75$ to -43 of the native promoter containing both Sp1 and EGR-1 was also used in the binding assays. Similarly, shear stress did not increase nuclear protein binding to this probe (data not shown). We also used an oligonucleotide containing an EGR-1 sequence as a probe. The binding of nuclear proteins to this probe was also not increased by shear stress (data not shown). Taken together, our data suggest that the shear stress-induced TF promoter activity is not due to an enhanced binding of Sp1 or EGR-1 to its target cis-element.

Shear stress induces the phosphorylation of Sp1. It has been shown that okadaic acid (OKA), an inhibitor of serine/threonine phosphatase, can induce the hyperphosphorylation of Sp1 (41). We investigated whether the application of shear stress,
A.

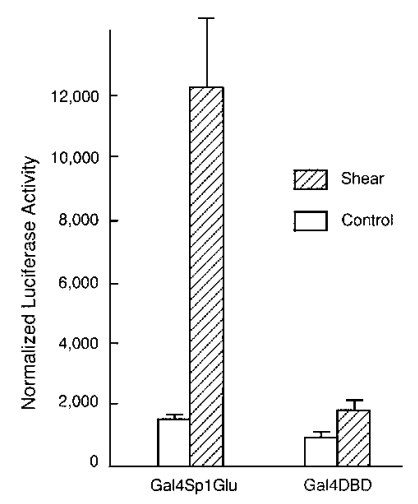

B.

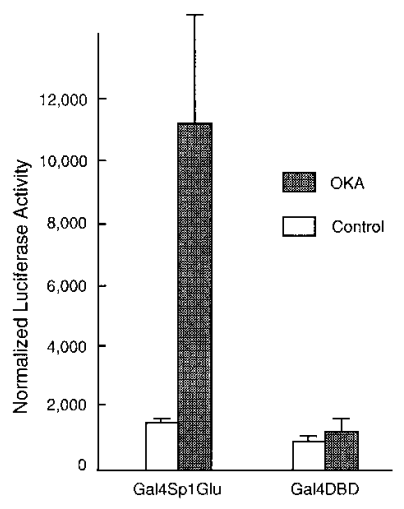

Figure 7. Shear stress and OKA increase the transcriptional activity of Sp1 in ECs. The plasmid 5xGal-Luc was cotransfected with either Gal4Sp1Glu or Gal4DBD into BAEC. The transfected cells were then either kept as static controls, subjected to a shear stress of 12 dyn $/ \mathrm{cm}^{2}$ for $8 \mathrm{~h} A$, or treated with $10 \mathrm{nM}$ OKA for $8 \mathrm{~h} B$ followed by luciferase activities assays. The bars represent the SD from three experiments.

like that of OKA, causes an increase in Sp1 phosphorylation. Nuclear proteins were prepared from both sheared cells and static controls for immunoblotting. As shown in Fig. $6 \mathrm{~A}$, polyclonal anti-human $\mathrm{Sp} 1$ recognized two protein bands with molecular mass of 105 and $95 \mathrm{kD}$ (42). The upper bands were identified to be the phosphorylated form of $\mathrm{Sp} 1$ as illustrated by the abolition of the bands by including alkaline phosphatase in the nuclear extracts (data not shown). The application of a shear stress of $12 \mathrm{dyn} / \mathrm{cm}^{2}$ induced an increase in Sp1 phosphorylation in the BAEC, indicated by the ratio of the phosphorylated form to that of the nonphosphorylated form. As positive controls, BAEC were treated with OKA, and indeed the phosphorylated Sp1 was increased (data not shown). Densitometry analysis of the results averaged from five separate experiments (Fig. $6 \mathrm{~B}$ ) indicated that the application of shear stress to ECs induces hyperphosphorylation of nuclear $\mathrm{Sp} 1$ in a transient manner. Compared to the static controls, there was a $30 \pm 7 \%$ and $35 \pm 12 \%$ increase in Sp1 phosphorylation in cells subjected to shear stress for $30 \mathrm{~min}$ and $1 \mathrm{~h}$, respectively. It decreased afterwards and the phosphorylated Sp1 in cells sheared for $12 \mathrm{~h}$ was only $75 \pm 15 \%$ of that in the static controls.

Shear stress increases Sp1 transcriptional activity. To further verify that an activated $\mathrm{Sp} 1$ is responsible for the induction of TF promoter in response to shear, we used a Gal4 fusion protein to study the transcriptional activity of $\mathrm{Sp} 1$ in response to shear stress. Plasmid Gal4Sp1Glu encoding the fusion protein of Gal4 DNA binding domain and the catalytic region A of Sp1, i.e., the glutamine-rich domain (38), was used in this study. We cotransfected Gal4Sp1Glu and 5xGal-Luc, a chimeric construct consisting of five copies of the Gal4 binding sequence and the luciferase reporter, into BAEC followed by the shear stress/luciferase assays. The control experiments were cells cotransfected with plasmid Gal4DBD, which encodes the Gal4 DNA binding domain (38), and 5xGal-Luc. As shown in Fig. $7 A$, the expression of Gal4Sp1Glu slightly increased the basal transcriptional activity of 5xGal-Luc. This is demonstrated by the comparison of luciferase activities in the 
two sets of cells (Gal4Sp1Glu versus Gal4DBD) under static conditions. Shear stress induced an eightfold increase in Sp1 transcriptional activity in the Gal4Sp1Glu-transfected cells. In contrast, the Gal4DBD-transfected cells responded minimally to shear stress. For BAEC transfected only with plasmid $5 x G a l-L u c$, the normalized luciferase activity was only at the background level and it was not induced by shear stress (data not shown). Since both OKA and shear stress induce the phosphorylation of Sp1, we were interested in determining whether OKA, like shear stress, can also induce Sp1 transcriptional activity. Fig. $7 \mathrm{~B}$ indicates that OKA indeed increased the transcriptional activity of Gal4Sp1Glu in BAEC sevenfold. This result demonstrates that hyperphosphorylation of $\mathrm{Sp} 1$ by shear stress may be involved in the elevation of TF transcriptional activity.

\section{Discussion}

In this report, the modulation of TF gene expression in ECs by shear stress is demonstrated by both the increased procoagulant activity and the increased TF mRNA in the sheared HUVEC (Figs. 1 and 2). These results indicate that fluid shear stress has similar effects as mitotic stimuli such as serum and phorbol ester in activating the TF gene. Functional analysis indicated that the 100-bp 5' promoter region of the TF gene containing three clusters of 12-bp GC-rich motifs (5'-C/GCGGGGGCGGGG/C-3') is shear-responsive (see PL6, Fig. 3). The Sp1 and EGR-1 elements overlap in these three motifs. Previous studies indicate that this region, lacking a serum responsive element (SRE) or TRE, responds to serum or TPA stimulation (15). TPA induction of the TF promoter in HeLa cells is mediated through binding of both EGR-1 and Sp1 in this GC-rich region (43). In that case, Sp1 contributes to the basal activity of TF promoter and responds weakly to TPA, whereas EGR-1 plays a major role in the induction by TPA. Our data indicate that site-specific mutations at the three Sp1 sites significantly reduced the basal activity, as well as the responsiveness to shear stress in ECs. In contrast, mutation at the EGR-1 sites did not affect the response of TF promoter to shear stress. Thus, the induction of the TF gene by shear stress involves distinct transcription factors and novel pathways, which are different from those used by chemical stimuli. A recent report by Khachigian et al. demonstrated that EGR-1 is required for the expression of various endothelial genes during vascular injury (44). All the model genes respond to TPA through an increase in EGR-1 binding. Interestingly, these genes, including PDGF-B, PDGF-A, and TF are all shear stress responsive and contain multiple $\mathrm{Sp} 1$ sites overlapping with EGR-1 sites. Our data indicate that EGR-1 may not be required for some of those genes to respond to shear stress, although it is required for induction by TPA. Instead, Sp1 interacting with the basic transcription machinery may constitute an ubiquitous gene regulatory mechanism in response to mechanical forces, such as fluid shear stress.

In addition to $\mathrm{Sp} 1$ sites, the TF promoter also includes ciselements TRE and $\kappa \mathrm{B}$, which are upstream to the GC-rich Sp1/EGR-1 region. Functional studies showed that the TRE and $\kappa \mathrm{B}$ sites mediate the induction by TNF- $\alpha$, IL- $1 \beta$, and LPS (45). Results from other investigators (32) and our previous studies $(30,33)$ have demonstrated that $\kappa \mathrm{B}$ and TRE are involved in the shear-induced expression of genes. The transcription factor AP-1, either a heterodimer of c-Fos and c-Jun or a homodimer of c-Jun, is activated by shear stress, which upregulates the TRE-containing promoters $(30,34) . \mathrm{kB} / \mathrm{Rel} \mathrm{p} 50$ p65 complex binds to the SSRE of the PDGF-B promoter in response to shear stress (32). It is interesting to note that TRE has no effect in the TF shear inducibility and that $\kappa \mathrm{B}$ has only a minor effect; $\kappa \mathrm{B}$ may enhance the $\mathrm{Sp} 1$ responses to shear stress by providing a higher basal level. Sp1, which is more proximal to the TATA box in the TF gene than any other identified shear stress responsive elements, plays a critical role in shear stress induction. These findings suggest that the tertiary structure of the promoter may determine the contribution of individual transcription factors to the promoter activity in response to shear stress. Furthermore, similar cis-elements may result in opposite effects if they are located in distinct genes. Malek et al. have shown that the shear stress downregulation of the ET-1 gene is mediated by a fragment between $-2.5 \mathrm{~kb}$ and $-2.9 \mathrm{~kb}$ of the ET-1 promoter (24). A GC-rich region is present in this $400 \mathrm{bp}$ region (46), that confers the negative modulation by both shear stress and TPA (24).

Fluid shear stress did not alter the interaction of nuclear extracts with the Sp1 and EGR-1 sequences (Fig. 5). This is not uncommon among cis-elements involved in the immediate early responses to mitotic stimuli. For example, SRE within the c-fos promoter is constitutively occupied and there is no apparent increase in its occupancy during induction by serum $(47,48)$. The findings that shear stress induces a hyperphosphorylation of Sp1 (Fig. 6), but does not change its interaction with DNA, are consistent with previous observations that phosphorylated and unphosphorylated Sp1 display identical binding characteristics (42). This shear stress-induced mechanism is different from the one involved in the induction of PDGF-A promoter by TPA: Khachigian et al. recently reported that the TPA-induced EGR-1 displaces Sp1 from the GC-rich region and thus activates the PDGF-A promoter in ECs (49). It is unclear whether the shear stress-induced TF promoter activity is due to the concurrent hyperphosphorylation on Sp1. One possible explanation is that $\mathrm{Sp} 1$ is already bound to the Sp1 site in the quiescent cells to provide the basal level activity of the TF promoter (Fig. 5). It is to be noted that the Sp1 in the control unstimulated cells had $33 \%$ phosphorylation, but little TF mRNA. The increase in phosphorylation in the sheared cells to $45 \%$ led to a fourfold induction of PL6 (Fig. 3), suggesting that relationship between Sp1 phosphorylation and transcriptional activation is nonlinear and that there may be a threshold level of phosphorylation for the induction of mRNA. This, however, remains to be investigated in depth. It has been shown that DNA-dependent protein kinase (DNA-PK) can rapidly phosphorylate Sp1 in vitro in a DNAdependent manner (42). Conceivably, shear stress leads to the activation of DNA-PK which phosphorylates Sp1 in a DNA binding-dependent manner. The GC-rich Sp1 binding sequence (i.e., the Sp1 site) must be present on the DNA for efficient phosphorylation to occur. The transient phosphorylation on Sp1 correlates well with the transient inductions of TF mRNA and procoagulant activity. The transient nature of these shear stress-induced events seems to be related to the delicate balance between these unidentified kinases and phosphatases. The increased phosphorylation in the initial phase is possibly due to the shear stress-activated kinases as suggested by several recent findings that shear stress induces mitogenactivated protein kinases (MAPK) modules, including c-Jun $\mathrm{NH}_{2}$-terminal kinases (JNK) and extracellular signal-regulated 
kinases (ERK) pathways $(50,51)$. Thus, a shear stress-activated DNA-PK cascade may be the upstream signaling pathway leading to the phosphorylation of Sp1, although DNA-PK may not be directly activated by MAPK pathways. If indeed DNA-PK can be activated by shear stress, it would be interesting to investigate whether other substrates of DNA-PK such as transcription factors Oct-1, Oct-2, tumor suppressor $\mathrm{p} 53$, and c-Myc (52) can be phosphorylated as well. In addition to shear stress, extracellular stimuli such as OKA can also increase $\mathrm{Sp1}$ phosphorylation (41). Interestingly, the posttranslational modification involving the phosphorylation of $\mathrm{Sp} 1$ was not induced by cytokines such as TNF (41), although TNF increased the TF promoter activity (9). This further indicates that different mechanisms are used to activate target genes by cytokines or by shear stress. OKA is an inhibitor of serine/threonine protein phosphatase. The treatment of ECs with OKA presumably inhibited a cellular protein phosphatase, and this might also be the mechanism for the induction of Sp1 transcriptional activity (Fig. $7 \mathrm{~B}$ ). Thus, it is possible that the declining phase of the shear stress-induced transient responses is due in part to the activation of cellular phosphatases.

While this report was reviewed, a study by Silverman et al., showed that pressure loading enhances TF activity in ECs (53), indicating mechanical stimuli other than shear stress can also augment the TF gene expression in ECs in vitro. The expression of TF mRNA in vascular ECs in vivo is undetectable. Whether these mechanical stimuli induction of the TF gene occur in the arterial tree is unclear, but TF has been located in atherosclerotic lesions $(5,6)$. A possible pathophysiological scenario is that the local hemodynamic forces lead to a lower threshold for the induction of the inflammation-related IE genes (e.g., MCP-1, TF, c-fos, and PDGF) in the ECs in lesionprone areas. The disturbed flow with low shear stresses and high shear gradients may increase IE gene expression and predispose these regions to the early events of atherosclerosis and thrombosis. In contrast, the endothelium in the lesion-resistant areas may be desensitized by the laminar flow with high shear stresses as indicated by the downregulation following constant shear in the in vitro experiments (29). As a consequence, these IE genes would be relatively quiescent in these lesion-resistant areas. The elucidation of these pathophysiological processes in the arterial trees deserves further investigation.

\section{Acknowledgments}

We thank Dr. Michael Green for providing Gal4Sp1Glu plasmid.

This work was supported in part by research grants HL19454, HL43026 (S. Chien), and HL56707 (J. Y-J. Shyy) from the National Heart, Lung and Blood Institute of the National Institutes of Health. We greatly appreciate the valuable discussion with Dr. Y-S. Li and the excellent technical assistance from Mr. Wayne Chen and Ms. Suli Yuan.

\section{References}

1. Nerem, R.M., D.G. Harrison, W.R. Taylor, and R.W. Alexander. 1993. Hemodynamics and vascular endothelial biology. J. Cardiovasc. Pharmacol. 21: S6-S10.

2. Nakashima, Y., A.S. Plump, E.W. Raines, J.L. Breslow, and R. Ross. 1994. ApoE-deficient mice develop lesions of all phases of atherosclerosis throughout the arterial tree. Arterioscler. Thromb. 14:133-140.

3. Walpola, P.L., A.I. Gotlieb, M.I. Cybulsky, and B.L. Langille. 1995. Expression of ICAM-1 and VCAM-1 and monocyte adherence in arteries exposed to altered shear stress. Arterioscler. Thromb. Vasc. Biol. 15:2-10.
4. Nemerson, Y. 1992. The tissue factor pathway of blood coagulation. Semin. Hematol. 29:170-176.

5. Wilcox, J.N., K.M. Smith, S.M. Schwartz, and D. Gordon. 1989. Localization of tisue factor in the normal vessel wall and in the atherosclerotic plaque. Proc. Natl. Acad. Sci. USA. 86:2839-2843.

6. Drake, T.A., J.H. Morrissey, and T.S. Edgington. 1989. Selective cellular expression of tissue factor in human tissues. Am. J. Pathol. 134:1087-1097.

7. Mamur, J.D., M. Rossikhina, A. Guha, B. Fyte, V. Friedrich, M. Mendlowitz, Y. Nemerson, and M.B. Taubman. 1993. Tissue factor is rapidly induced in arterial smooth muscle after balloon injury. J. Clin. Invest. 91:2253-2259.

8. Scarpati, E.M., and J.E. Sadler. 1989. Regulation of endothelial cell coagulant properties. J. Biol. Chem. 264:20705-20713.

9. Conway, E.M, R. Bach, R.D. Rosenberg, and W.H. Konigsberg. 1989. Tumor necrosis factor enhances expression of tissue factor mRNA in endothelial cells. Thromb. Res. 53:231-241.

10. Crossman, D.C., D.P. Carr, E.G.D. Tuddenham, J.D. Pearson, and J.H. McVey. 1990. The regulation of tissue factor mRNA in human endothelial cells in response to endotoxin or phorbol ester. J. Biol. Chem. 265:9782-9787.

11. Nawroth, P.P., D.A. Handley, C.T. Esmon, and D.M. Stern. 1986. Interleukin 1 induces endothelial cell procoagulant while suppressing cell-surface anticoagulant activity. Proc. Natl. Acad. Sci. USA. 83:3460-3464.

12. Hartzell, S., K. Ryder, A. Lanahan, L.F. Kau, and D. Nathans. 1989. A growth factor-responsive gene of murine Balb/c $3 \mathrm{~T} 3$ cells encodes a protein homologous to human tissue factor. Mol. Cell. Biol. 9:2567-2573.

13. Bloem, L., J.L. Chen, W.H. Konigsberg, and R. Bach. 1989. Serum stimulation of quiescent human fibroblasts induces the synthesis of tissue factor mRNA followed by the appearance of tissue factor antigen and procoagulant activity. J. Cell. Physiol. 139:418-423.

14. Mackman, N., B. Fowler, T.S. Edgington, and J.H. Morrissey. 1990. Functional analysis of the human tissue factor promoter and induction by serum. Proc. Natl. Acad. Sci. USA. 87:2254-2258.

15. Mackman, N., J.H. Morrissey, B. Fowler, and T.S. Edgington. 1989. Complete sequence of the human tissue factor gene, a highly regulated cellular receptor that initiates the coagulation protease cascade. Biochemistry. 28:17551762 .

16. Cui, M.Z., G.C.N. Parry, T.S. Edgington, and N. Mackman. 1994. Regulation of tissue factor gene expression in epithelial cells. Arterioscler. Thromb. 14:807-814.

17. Patrick, C.W., Jr., and L.V. McIntire. 1995. Shear stress and cyclic strain modulation of gene expression in vascular endothelial cells. Blood Purif. 13: $112-124$.

18. Davies, P.F. 1995. Flow-mediated endothelial mechanotransduction. Physiol. Rev. 75:519-560.

19. Dimond, S.L., J.B. Sharefkin, C. Diffenbach, K. Fraier-Scott, L.V. McIntire, and S.G. Eskin. 1990. Tissue plasminogen activator messenger RNA levels increase in cultured human endothelial cells exposed to lamilar shear stress. J. Cell. Physiol. 143:364-371.

20. Hsieh, H-J., N-Q. Li, and J.A. Frangos. 1992. Shear-induced plateletderived growth factor gene expression in human endothelial cells is mediated by protein kinase C. J. Cell. Physiol. 150:552-558.

21. Hsieh, H-J., N-Q. Li, and J.A. Frangos. 1993. Pulsatile and steady flow induces c-fos expression in human endothelial cells. J. Cell. Physiol. 154:143151

22. Nagel, T., N. Resnick, W.J. Atkinson, C.F. Dewey, and M.A. Gimbrone, Jr. 1994. Shear stress selectively upregulates intercellular adhesion molecule-1 expression in cultured human vascular endothelial cells. J. Clin. Invest. 94:885891.

23. Morita, T., H. Kurihara, K. Maemura, M. Yoshizumi, and Y. Yazaki. 1993. Disruption of cytoskeletal structures mediates shear stress-induced endothelin-1 gene expression in cultured porcine aortic endothelial cells. J. Clin. Invest. 92:1706-1712.

24. Malek, A.M., A.L. Greene, and S. Izumo. 1993. Regulation of endothelin 1 gene by fluid shear stress is transcriptionally mediated and independent of protein kinase C and cAMP. Proc. Natl. Acad. Sci. USA. 90:5999-6003.

25. Malek, A.M., G.H. Gibbons, V.J. Dzau, and S. Izumo. 1993. Fluid shear stress differentially modulates expression of genes encoding basic fibroblast growth factor and platelet-derived growth factor B chain in vascular endothelium. J. Clin. Invest. 92:2013-2021.

26. Ohtsuka, A., J. Ando, R. Korenaga, A. Kamiya, N. Toyama-Sorimachi, and M. Miyasak. 1993. The effect of flow on the expression of vascular adhesion molecule-1 by cultured mouse endothelial cells. Biochem. Biophys. Res. Commun. 193:303-310.

27. Morita, T., M. Yoshizumi, H. Kurihara, K. Maemura, R. Nagai, and Y. Yazaki. 1993. Shear stress increases heparin-binding epidermal growth factorlike growth factor mRNA levels in human vascular endothelial cells. Biochem. Biophys. Res. Commun. 197:256-262.

28. Ohno, M. J.P. Cooke, V.J. Dzau, and G.H. Gibbons. 1995. Fluid shear stress induces endothelial transforming growth factor $\beta-1$ transcription and production. Modulation by potassium channel blockade. J. Clin. Invest. 95:13631369.

29. Shyy, Y-J., H.J. Hsieh, S. Usami, and S. Chien. 1994. Fluid shear stress induces a biphasic response of human monocyte chemotactic protein 1 gene ex- 
pression in vascular endothelium. Proc. Natl. Acad. Sci. USA. 91:4678-4682.

30. Shyy, Y-J., M.C. Lin, J. Han, Y. Lu, M. Petrime, and S. Chien. 1995. The cis-acting phorbol ester "12-O-tetradecanoylphorbol 13-acetate"-responsive element is involved in shear stress-induced monocyte chemotactic protein 1 gene expression. Proc. Natl. Acad. Sci. USA. 92:8069-8073.

31. Resnick, N., T. Collins, W. Atkinson, D.T. Bonthron, C.F. Dewey, Jr., and M.A. Gimbrone, Jr. 1993. Platelet-derived growth factor Bchain promoter contains a cis-acting fluid shear-stress-responsive element. Proc. Natl. Acad. Sci. USA. 86:2839-2843.

32. Khachigian, L.M., N. Resnick, M.A. Gimbrone, Jr., and T. Collins. 1995. Nuclear factor- $\kappa \mathrm{B}$ interacts functionally with the platelet-derived growth factor B-chain shear-stress response element in vascular endothelial cells exposed to fluid shear stress. J. Clin. Invest. 96:1169-1175.

33. Shyy, Y-J., Y-S. Li, M.C. Lin, W. Chen, S. Yuan, S. Usami, and S. Chien. 1995. Multiple cis-elements mediate shear stress-induced gene expression. $J$. Biomech. 28:1451-1457.

34. Lan, Q., K.O. Mercurius, and P.F. Davis. 1994. Stimulation of transcription factors NFкB and AP1 in endothelial cells subjected to shear stress. Biochem. Biophys. Res. Commun. 201:950-956.

35. Jaffe, E.A., R.L. Nachman, G.C. Becker, and C.R. Minick. 1973. Culture of human EC derived from umbilical veins. J. Clin. Invest. 52:2745-2754.

36. Frangos, J.A., S.G. Eskin, L.V. McIntire, and C.L. Ives. 1985. Flow effects on prostacyclin production by cultured human endothelial cells. Science (Wash. DC). 227:1477-1479.

37. Chomczynski, P., and N. Sacchi. 1987. Single-step method of RNA isolation by acid guanidinium thiocyanate-phenol-chloroform extraction. Anal. Biochem. 162:156-159.

38. Southgate, C.D., and M.R. Green. 1991. The HIV-1 Tat protein activates transcriptional from an upstream DNA-binding site: implications for Tat function. Genes Dev. 5: 2496-2507.

39. Sadowski, I., J. Ma, S. Triezenberg, and M. Ptashne. 1988. Gal4-VP16 is an unusually potent transcriptional activator. Nature (Lond.). 335: 563-564.

40. Ausubel, F.M., R. Brent, R.E. Kingston, D.D. Moore, J.G. Seidman, J.A. Smith, and K. Struhl, editors. 1987. Current Protocols in Molecular Biology. John Wiley \& Sons Inc., New York. 18.34.

41. Vlach, J., A. Garcia, J.M. Jacque, M.S. Rodriguez, S. Michelson, and J.L. Virelizier. 1995. Induction of Sp1 phosphorylation and NF-кB-independent
HIV promoter domain activity in T lymphocytes stimulated by okadaic acid. Virology. 208:753-761.

42. Jackson, S.P., J.J. MacDonald, S. Lees-Miller, and R. Tjian. 1990. GC box binding induces phosphorylation of Sp1 by a DNA-dependent protein kinase. Cell. 63:155-165.

43. Cui, M.Z., G.C.N. Parry, P. Oeth, H. Larson, M. Smith, R.P. Huang, E.D. Adamson, and N. Mackman. 1996. Transcriptional regulation of the tissue factor gene in human epithelial cell is mediated by Sp1 and EGR-1. J. Biol. Chem. 271:2731-2739.

44. Khachigian, L.M., V. Lindner, A.J. Williams, and T. Collins. 1996. Egr1-induced endothelial gene expression: a common theme in vascular injury. Science (Wash. DC). 271:1427-1431,

45. Parry, G.C., and N. Mackman. 1995. Transcriptional regulation of tissue factor expression in human endothelial cells. Arterioscler. Thromb. Vasc. Biol 15:612-621.

46. Inoue, A., M. Yanagisawa, Y. Takuwa, Y. Mitsui, M. Kobayashi, and T. Masaki. 1989. The human preproendothelin-1 gene. Complete nucleotide sequence and regulation of expression. J. Biol. Chem. 264:14954-14959.

47. Hipskind, R.A., and A. Nordheim. 1991. In vitro transcriptional analysis of the human c-fos proto-oncogene. J. Biol. Chem. 266:19572-19582.

48. Hipskind, R.A., and A. Nordheim. 1991. Functional dissection in vitro of the human c-fos promoter. J. Biol. Chem. 266:19583-19592.

49. Khachigian, L.M., A.J. Williams, and T. Collins. 1995. Interplay of Sp1 and EGR-1 in the proximal platelet-derived growth factor A-chain promoter in cultured vascular endothelial cells. J. Biol. Chem. 270:27679-27686.

50. Li, Y-S., J.Y. Shyy, S. Li, J.D. Lee, B. Su, M. Karin, and S. Chien. 1996. The Ras/JNK pathway are involved in the shear stress-induced gene expression. Mol. Cell Biol. 16:5947-5954.

51. Tseng, H., T.E. Peterson, and B.C. Berk. 1995. Fluid shear stress stimulates mitogen-activated protein kinase in endothelial cells. Circ. Res. 77:869878

52. Finnie, N., T. Gottlieb, K. Hartley, and S.P. Jackson. 1993. Transcription factor phosphorylation by the DNA-dependent protein kinase. Biochem. Soc Trans. 21:930-935.

53. Silverman, M.D., M.M. Samet, and P.I. Lelkes. 1996. Pressure modulates tissue factor expression in human aortic and vena endothelial cells. J. Vascular Res. 33 (Suppl 1):93. 